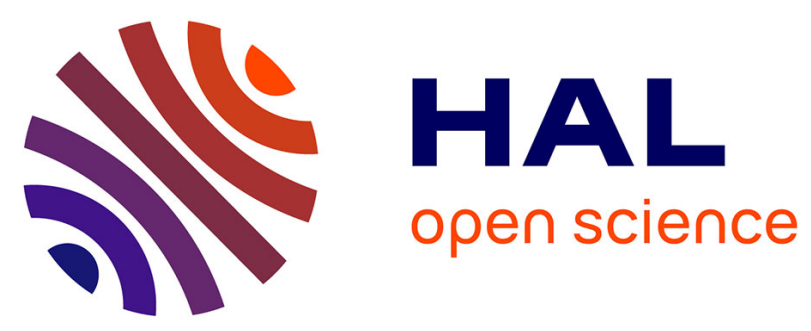

\title{
Modulation of cell sensitivity to antitumor agents by targeting survival pathways
}

\author{
Paola Perego, Giacomo Cossa, Valentina Zuco, Franco Zunino
}

\section{To cite this version:}

Paola Perego, Giacomo Cossa, Valentina Zuco, Franco Zunino. Modulation of cell sensitivity to antitumor agents by targeting survival pathways. Biochemical Pharmacology, 2010, 80 (10), pp.1459. 10.1016/j.bcp.2010.07.030 . hal-00626234

\section{HAL Id: hal-00626234 https://hal.science/hal-00626234}

Submitted on 24 Sep 2011

HAL is a multi-disciplinary open access archive for the deposit and dissemination of scientific research documents, whether they are published or not. The documents may come from teaching and research institutions in France or abroad, or from public or private research centers.
L'archive ouverte pluridisciplinaire HAL, est destinée au dépôt et à la diffusion de documents scientifiques de niveau recherche, publiés ou non, émanant des établissements d'enseignement et de recherche français ou étrangers, des laboratoires publics ou privés. 


\section{Accepted Manuscript}

Title: Modulation of cell sensitivity to antitumor agents by targeting survival pathways

Authors: Paola Perego, Giacomo Cossa, Valentina Zuco, Franco Zunino

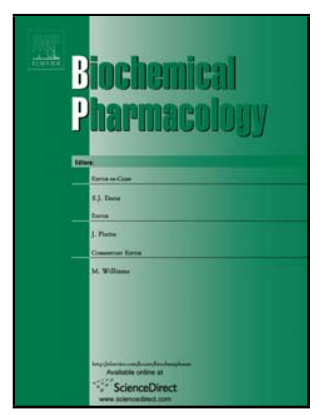

PII:

S0006-2952(10)00568-X

DOI: doi:10.1016/j.bcp.2010.07.030

Reference: BCP 10663

To appear in: $\quad B C P$

Received date: $\quad 27-5-2010$

Revised date: 20-7-2010

Accepted date: $\quad$ 23-7-2010

Please cite this article as: Perego P, Cossa G, Zuco V, Zunino F, Modulation of cell sensitivity to antitumor agents by targeting survival pathways, Biochemical Pharmacology (2010), doi:10.1016/j.bcp.2010.07.030

This is a PDF file of an unedited manuscript that has been accepted for publication. As a service to our customers we are providing this early version of the manuscript. The manuscript will undergo copyediting, typesetting, and review of the resulting proof before it is published in its final form. Please note that during the production process errors may be discovered which could affect the content, and all legal disclaimers that apply to the journal pertain. 
Modulation of cell sensitivity to antitumor agents by targeting survival pathways

Paola Perego, Giacomo Cossa, Valentina Zuco and Franco Zunino

Molecular Pharmacology Unit, Department of Experimental Oncology and Molecular Medicine, Fondazione IRCCS Istituto Nazionale Tumori, Via Venezian 1, 20133 Milan, Italy 
Running title: Targeting survival pathways

Corresponding author: Franco Zunino, Fondazione IRCCS Istituto Nazionale Tumori, Via Venezian 1, 20133 Milan, Italy. Tel. +39-02-23902267, Fax +39-02-23902692, e.mail franco.zunino@istitutotumori.mi.it

\begin{abstract}
Abbreviations: AMPK, AMP-dependent protein kinase; ER, endoplasmic reticulum; ERK, extracellular signal-regulated kinases; GRP78, glucose-regulated protein 78; HDAC, histone deacetylase; mTOR, mammalian target of rapamycin; MAPK, mitogen-activated protein kinase; PI3K, phosphoinositide 3-kinase; SAPK/JNK, stress-activated protein kinase/c-Jun Nterminal kinases; RTK, receptor tyrosine kinase; UPR, unfolded protein response; VEGF, vascular endothelial growth factor.
\end{abstract}




\section{Abstract}

The advent of drugs targeting tumor-associated prosurvival alterations of cancer cells has changed the interest of antitumor drug development from cytotoxic drugs to target-specific agents. Although single-agent therapy with molecularly targeted agents has shown limited success in tumor growth control, a promising strategy is represented by the development of rational combinations of target-specific agents and conventional antitumor drugs. Activation of survival/antiapoptotic pathways is a common feature of cancer cells that converge in the development of cellular resistance to cytotoxic agents. The survival pathways implicated in cellular response to drug treatment are primarily PI3K/Akt and Ras/MAPK, which also mediate the signalling activated by growth factors and play a role in the regulation of critical processes including cell proliferation, metabolism, apoptosis and angiogenesis. Inhibitors of PI3K, Akt and mTOR have been shown to sensitize selected tumor cells to cytotoxic drugs through multiple downstream effects. Moreover, the MAPK pathway, also implicated in the regulation of gene expression in response to stress stimuli, can interfere with the chemotherapy-induced proapoptotic signals. Targeting Hsp90, which acts as a molecular chaperone for survival factors including Akt, may have the potential advantage to simultaneously block multiple oncogenic pathways. Overall, the available evidence supports the interest of rationally designed approaches to enhance the efficacy of conventional antitumor treatments through the inhibition of survival pathways and the notion that the concomitant targeting of multiple pathways may be a successful strategy to deal with tumor heterogeneity and to overcome drug resistance of tumor cells.

Key words: Antitumor agents, targeted therapy, survival pathways, drug combinations 


\section{Introduction}

The limited success of antitumor therapy with conventional agents reflects the presence or development of resistance of tumor cells. Most of the conventional antitumor drugs target fundamental cellular processes involving DNA functions or cell division. A variety of novel agents, able to interfere with specific oncogenic processes or with relevant cellular targets, have been developed in the hope to identify treatment strategies characterized by improved efficacy and reduced toxic side effects. However, the single-agent therapy with molecularly targeted agents (small molecule or biological) has shown a limited efficacy, because the alterations of the most common diseases are very complex and, in general, solid tumors exhibit a large heterogeneity. Therefore, drug resistance is a common problem involving both cytotoxic and targeted agents $[1,2]$.

A well-established principle of cancer therapy to overcome tumor resistance is the combination of non-cross-resistant drugs characterized by different mechanisms of action and non-overlapping profiles of toxicity. The knowledge of molecular alterations and features of tumors and the identification of mechanisms of tumor resistance provide the opportunity to test novel rationally designed drug combinations. With the emergence of novel targeted agents with well-defined mechanisms of action, new effective drug combinations could be explored on the basis of tumor type-specific alterations which may be relevant in determining the resistant phenotype. Tumor-specific drug resistance has been ascribed to mutational events (intrinsic or drug-induced), to karyotypic changes or to epigenetic alterations. Cellular response to cytotoxic agents may involve the activation of defence systems and the modulation of signalling pathways implicated in the control of tumor growth or progression. The prosurvival cell response is of particular relevance at subtoxic concentrations, because it may result in survival of resistant cells. Thus, the combination of drugs targeting survival 
pathways appears to be promising for tumor therapy in an attempt to reduce cell ability to survive under stress conditions induced by hypoxia or chemotherapy. However, suppression of a single pathway may be inadequate to provide a general impact in antitumor therapy efficacy, because multiple features or alterations of tumor cells contribute to the sensitivity of targeted agents. This article focuses specifically on the available evidence supporting the interest of combination therapy that interferes with survival signals, as a promising strategy to optimize the application and rational incorporation of novel target-specific agents into a variety of therapeutic approaches.

\section{PI3K-Akt-mTOR pathway}

The deregulation of oncogenic signalling pathways provides survival advantages and can influence the sensitivity of tumor cells to antitumor agents. The aberrant signalling activated by overexpressed or mutant growth factor receptors is mainly mediated by the PI3K-Akt-mTOR and the Ras-MAPK networks. The PI3K-Akt-mTOR pathway plays a key role in regulating critical cellular functions including cell growth and metabolism $[3,4]$. The pathway is activated in several human cancers and inappropriate activation can result from aberrant activation of RTKs or from specific mutations of components of the pathway itself. Although three classes of PI3Ks are known, class IA appears the most critical in regulation of tumor cell growth and proliferation [3]. These enzymes are lipid kinases which phosphorylate the 3' $\mathrm{OH}$ of phoshoinositols in response to growth factors and cytokines. PI3Ks are heterodimers composed of regulatory subunits (p85, involved in the interaction with RTKs) and catalytic subunits (p110) releasing $\mathrm{PIP}_{3}$, a phospholipid acting as a potent second messenger able to recruit Akt, the critical mediator of the signalling cascade [4]. The cellular availability of $\mathrm{PIP}_{3}$ is reduced by the phosphatase activity of the tumor suppressor gene PTEN [5]. Since the activation of the PI3K pathway and signalling can occur at multiple levels (e.g., 
mutated or overexpressed RTKs and Akt), the PI3K signalling cascade has been referred to as a "super-highway" [6]. Akt has been implicated in the regulation of the transcriptional activity of the antiapoptotic NF- $\mathrm{BB}$, by inducing activation of I $\mathrm{KK}$ and subsequent phosphorylation

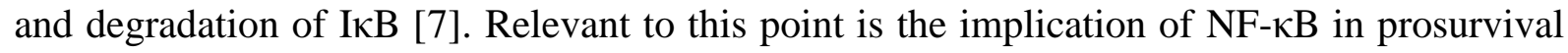
response following treatment with cytotoxic agents (e.g., cisplatin) [8]. Indeed, NF-кB is recognized to be a mediator of drug resistance by inhibiting drug-induced apoptosis.

In addition, Akt activates mTOR, which is the major effector of the signalling cascade. mTOR has been implicated in the regulation of critical cellular processes, including mRNAtranslation and metabolism. mTOR is known to form two complexes, i.e. mTORC1, which is activated by growth factors and nutrients, and mTORC2, which phosphorylates Akt, thereby contributing, through a feedback mechanism, to the continuous activation of the PI3K-AktmTOR axis [9]. The partecipation of the PI3K pathway in a large number of cellular processes influencing cell growth, survival and resistance to chemo- and radiotherapy have stimulated considerable efforts to identify inhibitors as potential therapeutic agents. Although the clinical experience with PI3K inhibitors is still limited, a number of compounds with variable degree of specificity have been developed [10]. The family of small molecules proposed as novel drugs is quite large and include also dual inhibitors, i.e. compounds capable of simultaneously inhibiting PI3K p110 $\alpha$ and mTOR [11]. The complexity of the malignant phenotype, the presence of multiple redundant pathways/networks and the crosstalks between pathways suggest that the use of PI3K inhibitors will be better exploited in combination with other agents. On the basis of the primary function of PI3K enzymes as mediator of signaling activated by growth factor receptors, it is conceivable that the modulation of this pathway critically affects the efficacy of growth factor receptor antagonists/inhibitors. An effective combination of the PI3K inhibitor GDC-0941 with HER2directed agents (trastuzumab and pertuzumab) has been recently reported in the treatment of 
breast carcinoma models [12]. The efficacy of the combination is related to the concomitant suppression of the PI3K-Akt and MAPK pathways. In addition, PI3K inhibitors have been shown to modulate cell sensitivity to cytotoxic agents (e.g., taxanes and platinum compounds). LY294002, a competitive inhibitor of the ATP-binding pocket of PI3Ks, has been combined with conventional cytotoxic agents in several in vitro and in vivo studies. The LY294002/cisplatin combination was effective in pancreatic cancer cells in which the inhibitor increased the apoptotic response through decreasing Akt-mediated BAD phosphorylation [13]. The non small cell lung cancer A549/CDDP cells, resistant to cisplatin and exhibiting an increased Akt1 expression, were also more sensitive to the same combination than the parental counterparts as a result of decreased phospho-Akt levels [14]. Triciribine is a potent and selective inhibitor of the kinase activity of all three Akt family members, without off-target effects on upstream activators. [15]. In an ovarian carcinoma cell line resistant to cisplatin (SKOV3/DDP), triciribine enhanced cisplatin cytoxicity and apoptosis induction, thus providing a target-specific way to overcome acquired resistance [16].

Given the role of Akt in regulation of mTOR, its inhibition is expected to have critical influence on multiple downstream events. Unfortunately, only a limited number of Akt inhibitors has been developed [3]. In contrast, mTOR inhibitors are now clinically available. In addition to rapamycin derivatives, which inhibit mTOR when complexed in mTORC1, novel ATP-competitive mTOR inhibitors targeting the kinase domain are expected to interfere with the activity of both mTORC1 and mTORC2 [17]. The water-soluble ester of rapamycin CCI-779 (Temsirolimus) has been used to restore cisplatin sensitivity in two lung cancer cell lines endowed with high levels of phospho-mTOR, phospho-Akt and other growth-related proteins, such as human telomerase reverse transcriptase and Cyclin D3 [18]. These data confirmed the previous observations indicating the ability of rapamycin to restore 
cisplatin sensitivity in platinum-resistant non small cell lung cancer cells [14]. Combined with cisplatin, RAD001 (Everolimus) induced a striking suppression of hepatocellular carcinoma growth both in vitro and in vivo, accompanied with a significant increase in the number of apoptotic cells $[19,20]$. The inhibition of mTOR was found effective in sensitizing cancer cells to other clinically relevant cytotoxic drugs [21,22].

Overall, these observations are consistent with the prosurvival role of PI3K-Akt pathway, which, through the activation of downstream effectors, may lead to drug resistance. The stress induced by cytotoxic agents, including cisplatin, may induce the modulation of different survival pathways, including the PI3K-Akt-mTOR axis [23,24]. A number of mutations or alterations in several tumor cells may cooperate to allow cell survival. The presence of redundant pathways may represent a resistance mechanism for specific inhibitors. In cells exhibiting activation of multiple pathways, the concomitant blockade of complementary pathways or the inhibition of specific steps of multicomponent pathways are expected to enhance antitumor effects. For example, resistance to the HER-2 inhibitor, lapatinib, as a consequence of PTEN mutation or activating mutations in PIK3CA, could be reversed by dual mTOR/PI3K inhibitors [25,26]. Similarly, breast cancer models, exhibiting resistance to trastuzumab, appear to be sensitive to mTOR inhibitors [27]. Dual inhibitors of the PI3K-Akt-mTOR pathway represent a promising class of agents able to overcome the feedback loops and to effectively inhibit the deregulated pathway $[3,28,29]$.

An indirect modulation of mTOR could be achieved by the activation of AMPK, which is a negative regulator of mTOR [26]. In contrast to rapamycin, metformin, an AMPK activator, decreases Akt activation resulting in an increased induction of apoptosis [30]. As expected on the basis of the known regulation of HIF-1 $\alpha$ expression, inhibition of mTOR results in an antiangiogenic effect through the decrease of VEGF expression. Since a similar effect on proangiogenic factors (VEGF and bFGF) has been reported for gimatecan and other 
novel camptothecins at low concentrations [31,32], it should be of potential interest to explore the efficacy of mTOR inhibitors with low doses of camptothecins (i.e. metronomic schedule of treatment which could be well tolerated).

\section{The MAPK pathway}

MAPKs are key players in the transduction of external survival signalling (e.g. growth factors-mediated) towards the cell nucleus. In particular, MAPKs couple extracellular stimuli with transcription of effector genes belonging to various processes including metabolism, survival and apoptosis. MAPK downstream effectors are other protein kinases, phospholipases, cytoskeletal members and transcription factors. The latter are usually cytosolic and, upon activation, migrate to the nucleus where they control the expression of specific target genes [33]. There are three different MAPK cascades, which include the SAPK/JNKs, the p38 and the ERKs cascade. While the ERK1/2 cascade is the main transducer of growth stimuli, SAPK/JNK and p38 cascades are mainly engaged in stress and inflammation responses [33]. Overall, the role of MAPK in determining cell fate after exposure to antitumor agents appears complex and dependent on the cellular context and the nature of the stimulus or damage. Indeed, inhibition of ERK1/2 activity has been shown to result in increased sensitivity to cisplatin in ovarian carcinoma cells [34,35], although other reports support that activation of ERK1/2 is required in cisplatin-induced apoptosis [36]. In ovarian carcinoma cells MAPKs, including ERK1/2, seem to play a protective role towards the cytotoxic effect of different DNA-damaging agents, such as platinum compounds and atypical retinoids $[37,38]$. Relevant to this point is the observation that the antiproliferative and apoptotic activity of the atypical retinoid ST1926 is enhanced by inhibiting the ERK1/2 pathway using PD98059 an inhibitor of MEK, which is an upstream regulator of ERK [39]. A prosurvival role for the ERK1/2 pathway is also documented by the analysis of the cellular 
bases of the combination between the atypical retinoid ST1926 and the EGF-R inhibitor gefitinib, which displayed a synergistic interaction in ovarian carcinoma cells [38]. Indeed, the enhanced apoptotic effect obtained with the combination appears to involve the ERK pathway, because a similar sensitization to apoptosis was produced by the MEK1/2 inhibitor UO126 [38].

The efficacy of MEK inhibitors themselves or their combination with other targetspecific agents appear to be dependent on the genetic/molecular background. The prosurvival role of ERK1/2 activation is often the result of a BRAF mutation, a common event in human cancer as it occurs in around $10 \%$ of tumors, the highest frequency being observed in melanoma. Mutant BRAF is capable of stimulating ERK1/2 signalling and promoting cell proliferation and transformation and represents a potential tumor-specific target [40-42]. Selective sensitivity to MEK inhibitors has been documented in BRAF mutant cells when compared to wild-type cells or cells carrying RAS mutations [43]. The heterogenous response of RAS mutant cells to MEK inhibitors has been linked to PIKCA and PTEN mutations, and the co-targeting of MEK and PI3K would be required for efficient inhibition of tumor growth [44]. Tyrosine kinase inhibitors induce downregulation of both PI3K and MAPK signalling pathways and the development of resistance to tyrosine kinase inhibitors may involve alterations of these downstream pathways. Thus, in the presence of mutations which may limit the efficacy of single-agent therapy, the combination of PI3K and MEK inhibitors may be effective [45].

The concomitant inhibition of PI3K and MAPK may cooperate in the modulation of the function of members of the Bcl-2 family [46]. Up-regulation of the antiapoptotic Bcl-2 family proteins has been implicated in drug resistance to various cytotoxic agents [47]. Indeed, Bcl-2 and related antiapoptotic proteins antagonize death signalling induced by cytotoxic agents. Inhibition of Bcl-2 function may result in a sensitization of resistant cells 
[21]. Bcl-2 itself is a downstream target of MAPKs, including ERK1/2, JNK and p38. Bcl-2 inhibitors (e.g., BH3 mimetics, including the orally available ABT-263) represent a novel class of promising antitumor agents which target a well-recognized mechanism implicated in tumor cell survival $[47,48]$. Relevant to this point are the observations indicating the efficacy of cotargeting of Bcl-2 and p38 MAPK [49].

\section{Hsp90}

Heat shock proteins have been implicated in stress response conditions and cellular resistance to cytotoxic agents. In particular, the Hsp90-mediated stabilization of various antiapoptotic proteins (Akt, survivin) provides a survival advantage under stressful conditions [50-53]. Although Hsp90 is not a tumor-specific target, this protein is overexpressed in tumor cells [54]. The interest of Hsp90 chaperone as a therapeutic target is related to its critical role in the regulation of the stability and function of oncogenic "client proteins", which are protected from degradation. In spite of the abundant expression of the protein in normal cells, the therapeutic selectivity for tumor cells could be achieved by exploiting oncogene addiction [55]. Since Hsp90 client proteins are signalling proteins implicated in survival/proliferation, including protein kinases, antiapoptotic proteins and transcription factors, its inhibition has the potential to simultaneously interfere with multiple signaling pathways [50-52,54,55]. Inhibition of the Hsp90 chaperone function results in destabilization and degradation of proteins involved in pathways essential for tumor cell survival; thus, Hsp90 inhibitors may be useful to improve the therapeutic efficacy of conventional cytotoxic agents through inhibition of survival pathways implicated in cellular response to drug treatment [56]. Hsp90 inhibitors may be effective in combination with Akt inhibitors [57]. Hsp90 inhibitors have been reported to sensitize ovarian carcinoma cells with high level of activated Akt and lung carcinoma with 
EGFR mutation to paclitaxel $[58,59]$. Several synergistic combinations of Hsp90 inhibitors with cytotoxic agents have been reported [60].

Up-regulation of heat shock proteins including Hsp90 is a major aspect of cell response following exposure to cisplatin [60]. Using a proteomic approach, we found Hsp90 up-regulation in the squamous cell carcinoma A431 cell line [61]. Moreover, global gene expression studies in response to cisplatin in a model organism evidenced induction of heat shock genes including the Hsp90 co-chaperones wos2 and sti1 [62]. Interestingly, wos2 is a critical regulator of wee 1 and cdc2, and it is homologue to the human p23 protein, which stabilizes Hsp90 in its ATP-bound form, thus extending the time in which Hsp90 can activate its client proteins [63].

\section{Metabolic alterations}

The PI3K-Akt pathway plays an important role in the regulation of multiple biological processes, including cell proliferation, angiogenesis and metabolism [3]. Deregulation of this pathway is implicated in malignant transformation and contributes to drug resistance. mTOR, the serine/threonine kinase which is activated downstream of the constitutively activated $\mathrm{PI} 3 \mathrm{~K} /$ Akt pathway, is implicated in the regulation of HIF-1 $\alpha$ expression in response to various stimuli $[64,65]$. The stabilization of HIF-1 $\alpha$ involves the interaction with Hsp90 [66]. HIF-1 $\alpha$, an oxygen-regulated heterodimeric transcription factor, is responsible for cellular adaptive response to hypoxia, because it enhances activation of hypoxia-inducible genes involved in angiogenesis, cell proliferation/survival and energy metabolism. Progression of solid tumors is associated with tumor cell adaptation to hypoxia, which contributes to the development of resistance to cytotoxic therapy [67]. The expression of the related factor, HIF$2 \alpha$, which is frequently elevated in human tumors and more critical factor in renal cell carcinoma, is dependent on mTORC2 [68]. Hypoxia-induced resistance appears to be a 
complex phenomenon involving not only modulation of apoptotic pathways, but also perturbation of energy metabolism, with up-regulation of glycolitic enzymes [69]. Indeed, HIF-1 $\alpha$ has been implicated as a major mediator of metabolic changes under hypoxic stress.

Several studies have emphasized the possibility to target the metabolic alterations of tumor cells to improve the efficacy of cytotoxic agents [69-71]. It is well known that most tumor cells are characterized by an increased dependency on glycolysis for anabolic reactions and energy generation, a feature which may represent an advantage for tumor growth. The combination of 2-deoxyglucose with metformin was found to produce inhibition of glycolysis and mitochondrial respiration of prostate cancer cells, resulting in a severe depletion of ATP and inhibition of cell viability [72]. Metformin is an activator of AMPK, a cellular energy sensor which is a negative regulator of mTOR [73,74]. Thus, given the regulatory role of AMPK in mTOR function and therefore in HIF- $1 \alpha$ expression, it is conceivable that modulation of AMPK may have an impact on glycolytic metabolism and cellular adaptation to hypoxia. However, several aspects of the crosstalk between various signalling pathways remain to be elucidated, thus providing a more rational basis to exploit the metabolic differences between tumor and normal cells. Although known inhibitors of glycolysis exhibit a marginal antitumor activity when used as single-agent therapy, several observations indicate that inhibition of glycolysis enhances the sensitivity to cytotoxic agents. 2-Deoxyglucose, a well-known inhibitor of glycolysis, was found to enhance the efficacy of cisplatin and of other cytotoxic agents with different mechanism of action (e.g., DNA damaging agents including doxorubicin) [75,76]. The synergistic interaction likely involves ATP depletion. A similar effect is produced by lonidamine, a derivative of indazole-3-carboxylic acid which impairs the energy metabolism and enhances the efficacy of cisplatin and other DNA damaging agents [77-79]. An alternative therapeutic strategy to inhibit tumor metabolism could be the use of inhibition of upstream regulators of metabolic pathways, including Akt, 
mTOR and HIF-1 $\alpha$ [80]. In cisplatin-resistant tumor cells expressing high levels of mTOR, treatment with rapamycin, a specific mTOR inhibitor, restores cisplatin sensitivity, an effect associated with downregulation of antiapoptotic (e.g., Bcl-2) and survival-related proteins (e.g., phospho-Akt). Inhibition of mTOR was found to sensitize hypoxic tumor cells to 2deoxyglucose [81]. This is consistent with the observation that HIF-1 $\alpha$ confers resistance to the glycolytic inhibitor [82]. Indeed, downregulation of Akt, mTOR and HIF-1 $\alpha$ increased sensitivity to glycolytic inhibitors, thus supporting the potential interest of targeting tumor metabolism by combining inhibitors of upstream regulators. Relevant to this point is the finding of a direct control of mitochondrial functions by mTOR [83]. Since the $\mathrm{PI} 3 \mathrm{~K} / \mathrm{Akt} / \mathrm{mTOR}$ pathway is implicated in the integration of multiple signals to regulate cell proliferation and metabolism, it is evident the interest of developing of agents targeting critical factors of the pathway and of possible combinations with metabolic modulators.

\section{Stress response}

A number of stress conditions occurring in tumor cells, as a consequence of hypoxia, oxidative stress or cytotoxic treatment, may result in accumulation of unfolded or misfolded proteins in the ER [84]. The biochemical response to this accumulation, known as UPR, is recognized as a protective process that favours cell survival by limiting the accumulation of unfolded/damaged proteins [85]. Hypoxia and glucose deprivation are relevant conditions of UPR activation, which also contributes to the development of drug resistance in solid tumors $[84,86]$. For this reason, UPR may be regarded as a potential target for therapeutic intervention. A number of agents have been reported to affect UPR response, by enhancing ER stress, thus favouring activation of cell death pathways [84]. They include proteasome inhibitors, which inhibit the degradation of misfolded proteins, or Hsp90 inhibitors, which cause destabilization of oncogenic (mutant or overexpressed) client proteins, resulting in 
enhanced ER stress. Relevant to this point is the observation that also HDAC6 plays a role in processing of misfolded proteins by deacetylating Hsp90, involved in stabilization of oncogenic mutant or overexpressed proteins, or by inducing protein degradation via the aggresome pathway, a process related to deacetylation of $\alpha$-tubulin $[87,88]$. Therefore, inhibition of HDAC6 by panHDAC inhibitors could result in enhancing ER stress by preventing protein processing. This effect could be better exploited in combination of HDAC inhibitors with Hsp90 inhibitors, as documented by the synergistic effects of the HDAC inhibitors panobinostat or vorinostat with curcumin, a recently recognized Hsp90 inhibitor [89]. We found that curcumin enhanced the proapoptotic activity of HDAC inhibitors at concentrations which were ineffective when each drug was used alone. However, it should be noted that the pleiotropic effects of curcumin on survival pathways may contribute to the efficacy of the combination [90].

An alternative approach to exploit the UPR as therapeutic target could be the inhibition of critical factors implicated in the stress response, which is expected to result in a reduced cell ability to adapt to stressful conditions. The downregulation of the ER chaperone GRP78, a key regulator of ER stress response, was recently reported to sensitize breast cancer cells to the proteasome inhibitor bortezomib and to UPR induced by the HDAC inhibitor panobinostat [91]. Indeed, GRP78 was found to be a substrate of HDAC6 [92], which is the cytosolic deacetylase also for other chaperones (i.e., Hsp90, Hsp70). Versipelostatin, a macrocyclic compound which inhibits the expression of GRP78 and impairs the glucose deprivation-induced stress response, exhibits selective cytotoxicity against glucose-deprived tumor cells [86,93]. A similar inhibition of activation of GRP78 during glucose deprivation has been reported for the antidiabetic biguanides, including metformin [86]. This finding is consistent with the synergistic proapoptotic effect of the combination of deoxyglucose and metformin observed in prostate carcinoma cells [72]. Such an interaction may have relevant 
implications for novel therapeutic strategies, because metformin has been reported to improve the efficacy of doxorubicin and to selectively kill cancer stem cells in breast carcinoma models [94]. This observation suggests that the metabolic features of cancer stem cells may be critical for survival of this cell subpopulation. Finally, it should be noted that several forms of stress, in particular alterations of cellular redox status [95], may be exploited to impair the ER stress response and to enhance cell death response.

\section{Conclusions}

The multiple mechanisms that have been implicated in acquired resistance to cytotoxic agents may be important in determining the degree of resistance, but insufficient to explain the intrinsic resistance, a common multifactorial phenomenon observed in most advanced solid tumors. The understanding of the molecular bases of the malignant phenotype indicates a critical role for several defence processes and survival pathways, and provides the opportunity to explore the role of agents targeting these pathways as modulators to improve the efficacy of cytotoxic therapy. The activation of such pathways may also be relevant in vivo due to the presence of survival stimuli generated in the tumor microenvironment.

The impact of survival pathways on cell response to conventional antitumor drugs, in particular cisplatin, has been examined in multiple cell systems representative of different tumor types $[14,20]$. Since drug resistance is a multi-factorial phenomenon, modulation of a single pathway has failed in part to lead to a complete overcoming of resistance. Although not all possible mechanisms have been studied in the same model, the available evidence supports that a marked sensitization can be obtained by co-targeting strategies using inhibitors of diverse pathways [46]. In this regard, it has to be noticed that the method used to evaluate synergism or the type of cell response investigated (e.g., cytotoxicity or apoptosis induction) may influence the magnitude of the observed effects. Although the sensitization to 
conventional cytotoxic agents achieved by targeting survival pathways is not impressive in several cases, the modulation may still have pharmacological relevance when the potentiation is produced by subtoxic (and, likely, well tolerated in vivo) concentrations of the agent used as modulator. It is conceivable that the synergistic interaction observed at subtoxic (i.e., ineffective when each drug was used alone) concentrations of rationally designed combinations may have therapeutic implications if incorporated in treatment regimens containing established agents [89].

The outcome of antitumor therapy following cytotoxic treatment is expected to depend on a number of critical factors including the nature, extent and persistence of the damaging effects. If the drug concentration at the tumor site is inadequate, e.g., as a consequence of the limited accessibility of the drug into solid tumor mass, the treatment may elicit cell cycle perturbations and only cytostatic effects. Under these conditions, tumor cells may respond with adaptive biochemical changes resulting in activation of defence mechanisms or survival pathways. Such changes may favour tumor progression through selection of subpopulation of resistant cells. The same limitation is theoretically possible during treatment with targetspecific agents, that usually require a prolonged exposure to achieve appreciable efficacy.

In addition, since the presence of multiple genetic alterations and the development of various resistance mechanisms confer tumor cell ability to survive under unfavourable conditions, it is likely that single-agent therapy may be not sufficient to control tumor growth, in spite of an effective inhibition of the cellular target. However, the success of targeted agents is related not only to the expected selectivity against tumor cells characterized by specific alterations or activation of oncogenic pathways, but also to the perception that the rational combination of such agents with novel or conventional drugs may be effective as a consequence of convergent inhibition of critical (survival) pathways. Thus, targeting pathways implicated in complex networks (Fig. 1) may be useful to provide synergistic 
effects in combination with cytotoxic agents and other antitumor therapies. Given the complexity of these pathways operating in closely interacting networks, it is conceivable that a multitarget approach may be the most successful strategy to improve the antitumor therapy. Available preclinical evidence supports that the concomitant inhibition of multiple pathways may be also effective in optimization of the use of targeted agents, in particular to overcome drug resistance related to specific alterations or hyperactivation of survival pathways $[96,97]$. These therapeutic strategies could be explored with the use of multitarget inhibitors or with the rational combination of synergistic targeted agents. It is likely that the efficacy of a cotargeting strategy may vary with the biological context and may depend on the relevance of the alteration in the mechanism of drug action. In the case of signal-transduction inhibitors, the cell sensitivity and drug selectivity reflect the constitutive activation of specific pathways and the dependence on the deregulated signalling for tumor growth and progression $[3,6,65]$. The biological characterization of tumor cells has already identify critical features of sensitive phenotypes. Thus, the inhibition of tumor-specific alterations may allow a significant therapeutic window.

Finally, since the energy-dependent survival pathways influence the malignant behaviour of tumor cells, targeting metabolic pathways may be effective also in preventing the metastatic disease [98]. The knowledge of the molecular features of individual tumors and the development of means of identifying tumor types responsive to selected combinations at preclinical level could overcome the limitations of empirical evaluations in the clinical setting [99].

\section{Acknowledgements}

This work was partially supported by the Associazione Italiana Ricerca sul Cancro, Milan; the Ministero della Salute, Rome; the Alleanza Contro il Cancro, Milan; the EU grant Chemores 
1 


\section{References}

1. Janne PA, Gray N, Settleman J. Factors underlying sensitivity of cancers to smallmolecule kinase inhibitors. Nature Rev 2009; 8:709-23.

2. Engelman JA, Settleman J. Acquired resistance to tyrosine kinase inhibitors during cancer therapy. Curr Opin Genet Dev 2008; 18:73-9.

3. Courtney KD, Corcoran RB, Engelman JA. The PI3K pathway as drug target in human cancer. J Clin Oncol 2010; 28:1075-83.

4. Liu P, Cheng H, Roberts TM, Zhao JJ. Targeting the phosphoinositide 3-kinase pathway in cancer. Nat Rev Drug Discov 2009; 8:627-44.

5. Yuan TL, Cantley LC. PI3K pathway alterations in cancer: variations on a theme. Oncogene 2008; 27:5497-510.

6. Workman P, Clarke PA, Raynaud FI, van Montfort RLM. Drugging the PI3 kinome: from chemical tools to drugs in the clinic. Cancer Res 2010; 70:2146-57.

7. Bai D, Ueno L, Vogt PK. Akt-mediated regulation of NFkB and the essentialness of NFkB for the oncogenicity of PI3K and Akt. Int J Cancer 2009; 125:2863-70.

8. Heffeter P, Jungwirth U, Jakupec M, Hartinger C, Galanski M, Elbling L, et al. Resistance against novel anticancer metal compounds: differences and similarities. Drug Resistance Updates 2008; 11:1-16.

9. Guertin DA, Sabatini DM. Defining the role of mTOR in cancer. Cancer Cell 2007; 12:922.

10. Gunn RM, Hailes HC. Insights into the PI3-K-PKB-mTOR signalling pathway from small molecules. J Chem Biol 2008; 1:49-62.

11. Fan Q, Fan QW, Knight ZA, Goldenberg DD, Yu W, Mostov KE, Stokoe D, et al. A dual PI3 kinase/mTOR inhibitor reveals emergent efficacy in glioma. Cancer Cell 2006; 9:341- 
9.

12. Yao E, Zhou W, Lee-Hoeflich ST, Truong T, Haverty PM, Eastham-Anderson J, et al. Suppression of HER2/HER3-mediated growth of breast cancer cells with combinations of GDC-0941 PI3K inhibitor, trastuzumab, and pertuzumab. Clin Cancer Res 2009; 15: 4147-56.

13. Fujiwara M, Izuishi K, Sano T, Hossain MA, Kimura S, Masaki T, et al. Modulating effect of the PI3-kinase inhibitor LY294002 on cisplatin in human pancreatic cancer cells. J Exp Clin Cancer Res 2008; 27:76-85.

14. Liu L-Z, Zhou X-D, Qian G, Shi X, Fang J, Jiang B-H. Akt1 amplification regulates cisplatin resistance in human lung cancer cells through the mammalian target of rapamycin/p70S6K1 pathway. Cancer Res 2007; 67:632532.

15. Kim D, Cheng GZ, Lindsley CW, Yang H, Cheng JQ. Targeting the phosphatidylinositol3 kinase/Akt pathway for the treatment of cancer. Curr Opin Investig Drugs 2005; 6:12508.

16. Zhang HY, Zhang PN, Sun H. Aberration of the PI3K/Akt/mTOR signalling in epithelial ovarian cancer and its implication in cisplatin-based chemotherapy. Eur J Obstet Gynecol Reprod Biol 2009; 146:81-6.

17. Yu K, Toral-Barza L, Shi C, Zhang WC, Lucas J, Shor B, et al. Biochemical, cellular, and in vivo activity of novel ATP-competitive and selective inhibitors of the mammalian target of rapamycin. Cancer Res 2009; 69:6232-40.

18. Wangpaichitr M, Wu C, You M, Kuo MT, Feun L, Lampidis T, et al. Inhibition of mTOR restores cisplatin sensitivity through down-regulation of growth and anti-apoptotic proteins. Eur J Pharmacol 2008; 591:124-7.

19. Tam KH, Yang ZF, Lau CK, Lam CT, Pang RWC, Poon RTP. Inhibition of mTOR enhances chemosensitivity in hepatocellular carcinoma. Cancer Lett 2009; 273:201-9. 
20. Leelawat K, Narong S, Udomchaiprasertkul W, Leelawat S, Tungpradubkul S. Inhibition of PI3K increases oxaliplatin sensitivity in cholangiocarcinoma cells. Cancer Cell Int 2009; 9:3-10

21. Marinov M, Ziogas A, Pardo OE, Tan LT, Dhillon T, Mauri FA, et al. Akt/mTOR pathway activation and BCL-2 family proteins modulate the sensitivity of human small cell lung cancer cells to RAD001. Clin Cancer Res 2009; 15:1277-87

22. Aissat N, Le Tourneau C, Ghoul A, Serova M, Bieche I, Lokiec F, et al. Antiproliferative effects of rapamycin as a single agent and in combination with carboplatin and paclitaxel in head and neck cancer cell lines. Cancer Chemother Pharmacol 2008; 62:305-13.

23. Tsuchida R, Das B, Yeger H, Koren G, Shibuya M, Thorner PS, et al. Cisplatin treatment increases survival and expansion of a highly tumorigenic side-population fraction by upregulating VEGF/Flt1 autocrine signaling. Oncogene 2008; 27:3923-34.

24. Winograd-Katz SE, Levitzki A. Cisplatin induces PKB/Akt activation and p38MAPK phosphorylation of the EGF receptor. Oncogene 2006; 25:7381-90.

25. Eichhorn PJ, Gili M, Scaltriti M, Serra V, Guzman M, Nijkamp W, et al. Phosphatidylinositol 3-kinase hyperactivation results in lapatinib resitance that is reversed by the mTOR/phosphatidylinositol 3-kinase inhibitor NVP-BEZ235. Cancer Res 2008; 68:9221-30.

26. Vazquez-Martin A, Oliveras-Ferraros C, del Barco S, Martin-Castillo B, Menéndez JA. mTOR inhibitors and the anti-diabetic biguanide metformin: new insights into the molecular management of breast cancer resistance to the HER2 tyrosine kinase inhibitor lapatinib (Tykerb). Clin Transl Oncol 2009; 11:455-9.

27. Berns K, Horlings HM, Hennessy BT, Madiredjo M, Hijmans EM, Beelen K, et al. A functional genetic approach identifies the PI3K pathway as a major determinant of trastuzumab resitance in breast cancer. Cancer Cell 2007; 12:295-402. 
28. Li T, Wang J, Wang X, Yang N, Chen S, Tong L, et al. WJD008, a dual PI3K/mTOR inhibitor, prevents PI3K signalling and inhibits the proliferation of transformed cells with oncogenic PI3K mutant. J Pharmacol Experim Ther 2010; in press.

29. Zitzmann K, von Ruden J, Brand S, Goke B, Lichtl J, Spottl G, et al. Compensatory activation of Akt in response to mTOR and Raf inhibitors - A rationale for dual-targeted therapy approaches in neuroendocrine tumor disease. Cancer Lett 2010; in press.

30. Zakikhani M, Blouin MJ, Piura E, Pollak MN. Metformin and rapamycin have distinct effects on the Akt pathway and proliferation in breast cancer cells. Breast Cancer Res Treat 2010; in press.

31. Petrangolini G, Pratesi G, De Cesare M, Supino R, Pisano C, Marcellini M, et al. Antiangiogenic effects of the novel camptothecin ST1481 (Gimatecan) in human tumor xenografts. Mol Cancer Res 2003; 1:863-70.

32. Pisano C, De Cesare M, Beretta GL, Zuco V, Pratesi G, Penco S, et al. Preclinical profile of antitumor activity of a novel hydrophilic camptothecin, ST1968. Mol Cancer Ther $2008 ; 7: 2051-9$.

33. Brozovic A, Osmak M. Activation of mitogen-activated protein kinases by cisplatin and their role in cisplatin-resistance. Cancer Lett 2007; 251:1-16.

34. Persons DL, Yazlovitskaya EM, Cui W, Pelling JC. Cisplatin-induced activation of mitogen-activated protein kinases in ovarian carcinoma cells: inhibition of extracellular signal-regulated kinase activity increases sensitivity to cisplatin. Clin Cancer Res 1999; $5: 1007-14$

35. Hayakawa J, Ohmichi M, Kurachi H, Ikegami H, Kimura A, Matsuoka T, et al. Inhibition of extracellular signal-regulated protein kinase or c-Jun N-terminal protein kinase cascade, differentially activated by cisplatin, sensitizes human ovarian cancer cell line. J Biol Chem 1999;274:31648-54. 
36. Wang X, Martindale JL, Holbrook NJ. Requirement for ERK activation in cisplatininduced apoptosis. J Biol Chem 2000; 275:39435-43.

37. Benedetti V, Perego P, Beretta GL, Corna E, Tinelli S, Righetti SC, et al. Modulation of serviva pathways in ovarian carcinoma cell lines resistant to platinum compounds. Mol Cancer Ther 2008; 7:679-87.

38. Zanchi C, Zuco V, Lanzi C, Supino R, Zunino F. Modulation of survival signaling pathways and persistence of the genotoxic stress as a basis for the synergistic interaction between the atipical retinoid ST1926 and the epidermal growth factor receptor inhibitor ZD1839. Cancer Res 2005; 65:2364-72.

39. Zuco V, Zanchi C, Cassinelli G, Lanzi C, Supino R, Pisano C, et al. Induction of apoptosis and stress response in ovarian carcinoma cell lines treated with ST1926, an atypical retinoid. Cell Death Differ 2004; 11:280-9.

40. Tsai J, Lee JT, Wang W, Zhang J, Cho H, Mamo S, et al. Discovery of a selective inhibitor of oncogenic B-Raf kinase with potent antimelanoma activity. PNAS 2008; 105:3041-6.

41. Sheperd C, Puzanov I, Sosman JA. B-RAF inhibitors: an evolving role in the therapy of malignant melanoma. Curr Oncol Rep 2010; 12:146-52.

42. Poulikakos PI, Zhang C, Bollag G, Shokat KM, Rosen N. RAF inhibitors transactivate RAF dimmers and ERK signalling in cells with wild-type BRAF. Nature 2010; 464:42730.

43. Solit DB, Garraway LA, Pratilas CA, Sawai A, Getz G, Basso A, et al. BRAF mutation predicts sensitivity to MEK inhibition. Nature 2006; 439:358-62.

44. Wee S, Jagani Z, Xiang KX, Loo A, Dorsch M, Yao YM, et al. P13K pathway activation mediates resistance to MEK inhibitors in KRAS mutant cancers. Cancer Res 2009; 69:4286-93. 
45. Engelman JA, Chen L, Tan X, Crosby K, Guimaraes AR, Upadhyay R, et al. Effective use of PI3K and MEK inhibitors to treat mutant Kras G12D and PIK3CA H1047R murine lung cancers. Nat Med 2008; 14:1351-6.

46. Grant S. Cotargeting survival signalling pathways in cancer. J Clin Invest 2008; 118:3003-6.

47. Pratesi G, Perego P, Zunino F. Role of Bcl-2 and its post-transcriptional modification in response to antitumor therapy. Biochem Pharmacol 2001; 61:381-6.

48. Ni Chonghaile T, Letai A. Mimicking the BH3 domain to kill cancer cells. Oncogene 2009; 27:S149-S57.

49. Keuling AM, Andrew SE, Tron VA. Inhibition of p38 MAPK enhances ABT-737-induced cell death in melanoma cell lines: novel regulation of PUMA. Pigment Cell Melanoma Res 2010; 23:430-40.

50. Porter JR, Fritz CC, Depew KM. Discovery and development of Hsp90 inhibitors: a promising pathway for cancer therapy. Curr Opin Chem Biol 2010; 14:1-9.

51. Whitesell L, Lindquist SL. Hsp90 and the chaperoning of cancer. Nat Rev Cancer 2005; $5: 761-72$.

52. Wandinger SK, Richter K, Buchner J. The Hsp90 chaperone machinery. J Biol Chem $2008 ; 283: 18473-7$.

53. Bali P, Pranpat M, Bradner J, Balasis M, Fiskus E, Guo F, et al. Inhibition of histone deacetylase 6 acetylase and disrupts the chaperone function of heat shock protein 90: a novel basis for antileukemia activity of histone deacetylase inhibitors. J Biol Chem 2005; 280:26729-34.

54. Porter JR, Fritz CC, Depew KM. Discovery and development of Hsp90 inhibitors: a promising pathway for cancer therapy. Curr Opin Chem Biol 2010; 14:412-20.

55. Workman P, Burrows F, Neckers L, Rosen N. Drugging the cancer chaperone HSP90. 
Combinatorial therapeutic exploitation of oncogene addiction and tumor stress. Ann NY Acad Sci USA 2007; 1113:202-16.

56. Persons DL, Yazlovitskaya EM, Cui W, Pelling JC. Cisplatin-induced activation of mitogen-activated protein kinases in ovarian carcinoma cells: inhibition of extracellular signal-regulated kinase activity increases sensitivity to cisplatin. Clin Cancer Res 1999; 5:1007-14.

57. Wong C, Chen S. Heat shock protein 90 inhibitors: new mode of therapy to overcome endocrine resistance. Cancer Res 2009; 69:8670-7.

58. Sain N, Krishnan B, Ormerod MG, De Rienzo A, Liu WM, Kaye SB, et al. Potentiation of paclitaxel activity by the Hsp90 inhibitor 17-allylamino-17-demethoxygeldanamycin in human ovarian carcinoma cell lines with high levels of activated Akt. Mol Cancer Ther 2006; 5:1197-208.

59. Sawai A, Chandarlapaty S, Greulich H, Gonen M, Ye Q, Arteaga CL, et al. Inhibition of Hsp90 down-regulates mutant epidermal growth factor receptor (EGFR) expression and sensitizes EGFR mutant tumors to paclitaxel. Cancer Res 2008; 68:589-96.

60. Beretta GL, Gatti L, Corna E, Carenini N, Zunino F, Perego P. Defining targets of modulation of human tumor cell response to cisplatin. J Inorg Biochem. 2008; 102:140615.

61. Castagna A, Antonioli P, Astner H, Hamdan M, Righetti SC, Perego P, et al. A proteomic approach to cisplatin resistance in the cervix squamous cell carcinoma cell line A431. Proteomics 2004; 4:3246-67.

62. Gatti L, Chen D, Beretta GL, Rustici G, Carenini N, Corna E, et al. Global gene expression of fission yeast in response to cisplatin. Cell Mol Life Sci 2004; 61:2253-63.

63. Ali MM, Roe SM, Vaughan CK, Meyer P, Panaretou B, Piper PW, et al. Crystal structure of an Hsp90-nucleotide-p23/Sba1 closed chaperone complex. Nature 2006; 440:1013-7. 
64. Hudson CC, Liu M, Chiang GG, Otterness DM, Loomis DC, Kaper F, et al. Regulation of hypoxia-inducible factor $1 \alpha$ expression and function by the mammalian target of rapamycin. Mol Cell Biol 2002; 22:7004-14.

65. Harada H, Itasaka S, Kizaka-Kondoh S, Shibuya K, Morinibu A, Shinomiya K, et al. The Akt/mTOR pathway assures the synthesis of HIF-1 $\alpha$ protein in a glucose- and reoxygenation-dependent manner in irradiated tumors. J Biol Chem 2009; 284:5332-42.

66. Zhou J, Schmid T, Frank R, Brune B. PI3K/Akt is required for heat shock proteins to protect hypoxia-inducible factor $1 \alpha$ from pVHL-independent degradation. J Biol Chem 2004; 279:13506-13.

67. Sullivan R, Paré GC, Frederiksen LJ, Semenza GL, Graham CH. Hypoxia-induced resistance to anticancer drugs is associated with decreased senescence and requires hypoxia-inducible factor-1 activity. Mol Cancer Ther 2008; 7:1961-73.

68. Toschi A, Lee E, Gadir N, Ohh M, Foster DA. Differential dependence of hypoxiainducible factors 1 alpha and 2 alpha on mTORC1 and mTORC2. J Biol Chem 2008; 283:34495-9.

69. Kroemer G, Pouyssegur J. Tumor cell metabolism: Cancer's Achilles' Heel. Cancer Cell $2008 ; 13: 472-82$.

70. Semenza GL. Targeting HIF-1 for cancer therapy. Nat Rev Cancer 2003; 3:721-32.

71. Tennant DA, Duran RV, Gottlieb E. Targeting metabolic transformation for cancer therapy. Nature Rev Cancer 2010; 10:267-77.

72. Sahra IB, Laurent K, Giuliano S, Larbret F, Ponzio G, Gounon P, et al. Targeting cancer cell metabolism: the combination of metformin and 2-deoxyglucose induces p53dependent apoptosis in prostate cancer cells. Cancer Res 2010; 70:2465-75.

73. Wang W, Guan K-L. AMP-activated protein kinase and cancer. Acta Physiol 2009; 196:55-63. 
74. Kisfalvi K, Eibl G, Sinnett-Smith J, Rozengurt E. Metformin disrupts crosstalk between G protein-coupled receptor and insulin receptor signaling systems and inhibits pancreatic cancer growth. Cancer Res 2009; 69:6539-45.

75. Simons AL, Fath MA, Mattson DM, Smith BJ, Walsh SA, Graham MM, et al. Enhanced response of human head and neck cancer, xenograft tumors to cisplatin combined with 2deoxy-D-glucose correlates with increased 18F-FDG uptake as determined by PET imaging. Int J Radiat Oncol Biol Phys 2007; 69:1222-30.

76. Zhang F, Aft RL. Chemosensitizing and cytotoxic effects of 2-deoxy-D-glucose on breast cancer cells. J Cancer Res Ther 2009; 1:S41-3.

77. De Cesare M, Pratesi G, Giusti A, Polizzi D, Zunino F. Stimulation of the apoptotic response as a basis for the therapeutic synergism of lonidamine and cisplatin in combination in human tumour xenografts. Br J Cancer 1998; 77:434-9.

78. Pratesi G, De Cesare M, Zunino F. Efficacy of lonidamine combined with different DNAdamaging agents in the treatment of the MX-1 tumor xenograft. Cancer Chemother Pharmacol 1996; 38:123-8.

79. Di Cosimo S, Ferretti G, Papaldo P, Carlini P, Fabi A, Cognetti F. Lonidamine: efficacy and safety in clinical trials for the treatment of solid tumors. Drugs Today 2003; 39:15774.

80. Loar P, Wahl H, Kshirsagar M, Gossner G, Griffith K, Liu JR. Inhibition of glycolysis enhances cisplatin-induced apoptosis in ovarian cancer cells. Am J Obstet Gynecol 2010; 202:371.

81. Wangpaichitr M, Savaraj N, Maher J, Kurtoglu M, Lampidis TJ. Intrinsically lower Akt, mammalian target of rapamycin, and hypoxia-inducible factor activity correlates with increased sensitivity to 2-deoxy-D-glucose under hypoxia in lung cancer cell lines. Mol Cancer Ther 2008; 7:1506-13. 
82. Maher JC, Wangpaichitr M, Savaraj N, Kurtoglu M, Lampidis TJ. Hypoxia-inducible factor-1 confers resistance to the glycolytic inhibitor 2-deoxy-D-glucose. Mol Cancer Ther 2007; 6:732-41.

83. Ramanathan A, Schreiber SL. Direct control of mitochondrial function by mTOR. PNAS $2009 ; 106: 22229-32$.

84. Healy SJM, Gorman AM, Mousavi-Shafaei P, Gupta S, Samali A. Targeting the endoplasmic reticulum-stress response as an anticancer strategy. Eur J Pharmacol 2009; 625:234-46.

85. Rouschop KMA, van den Beucken T, Dubois L, Niessen H, Bussink J, Savelkouls K, et al. The unfolded protein response protects human tumor cells during hypoxia thorugh regulation of the autophagy genes MAPILC3B and ATG5. J Clin Invest 2010; 120:127-41.

86. Saito S, Furuno A, Sakurai J, Sakamoto A, Park H-R, Shin-ya K, et al. Chemical genomics identifies the unfolded protein response as a target for selective cancer cell killing during glucose deprivation. Cancer Res 2009; 69:4225-34.

87. Kawaguchi Y, Kovacs JJ, McLaurin A, Vance JM, Ito A, Yao TP. The deacetylase HDAC6 regulates aggresome formation and cell viability in response to misfolded protein stress. Cell 2003; 115:727-38.

88. Bots M, Johnstone RW. Rational combinations using HDAC inhibitors. Clin Cancer Res $2009 ; 15: 3970-3977$.

89. Giommarelli C, Zuco V, Favini E, Pisano C, Dal Piaz F, De Tommasi N, et al. The enhancement of antiproliferative and proapoptotic activity of HDAC inhibitors by curcumin is mediated by Hsp90 inhibition. Cell Mol Life Sci 2010; 67:995-1004.

90. Reuter S, Eifes S, Dicato M, Aggarwal BB, Diederich M. Modulation of anti-apoptotic and survival pathways by curcumin as a strategy to induce apoptosis in cancer cells. Biochem Pharmacol 2008; 76:1340-51. 
91. Rao R, Nalluri S, Kolhe R, Yang Y, Fiskus W, Chen J, et al. Treatment with panobinostat induces glucose-regulated protein 78 acetylation and endoplasmic reticulum stress in breast cancer cells. Mol Cancer Ther 2010; 9:942-52.

92. Kahali S, Sarcar B, Fang B, Williams ES, Koomen JM, Tofilon PJ, et al. Activation of the unfolded protein response contributes toward the antitumor activity of vorinostat. Neoplasia 2010; 12:80-6.

93. Park HR, Tomida A, Sato S, Tsukumo Y, Yun J, Yamori T, et al. Effect on tumor cells of blocking survival response to glucose deprivation. J Natl Cancer Inst 2004; 96:1300-10.

94. Hirsch HA, Iliopoulos D, Tsichlis PN, Struhl K. Metformin selectively targets cancer stem cells, and acts together with chemotherapy to block tumor growth and prolong remission. Cancer Res 2009; 69:7507-11.

95. Giommarelli C, Corti A, Supino R, Favini E, Paolicchi A, Pompella A, et al. $\gamma$ glutamyltransferase-dependent resi stance to arsenic trioxide in melanoma cells and cellular sensitization by ascorbic acid. Free Rad Biol Med 2009; 46:1516-26.

96. Bao R, Lai C-J, Wang D-G, Qu H, Yin L, Zifcak B, et al. Targeting heat shock protein 90 with CUDC-305 overcomes erlotinib resistance in non-small cell lung cancer. Mol Cancer Ther 2009; 8:3296-306.

97. Ghayad SE, Vendrell JA, Ben Larbi S, Dumontet C, Bieche I, Cohen PA. Endocrine resistance associated with activated ErbB system in breast cancer cells is reversed by inhibiting MAPK or PI3K/Akt signaling pathways. Int J Cancer 2010; 126:545-62.

98. Pisano C, Vesci L, Milazzo FM, Guglielmi MB, Foderà R, Barbarino M, et al. Metabolic approach to the enhancement of antitumor effect of chemotherapy: a key role of acetyl-Lcarnitine. Clin Cancer Res 2010; in press.

99. Dancey JE, Chen HX. Strategies for optimizing combinations of molecularly targeted anticancer agents. Nature Rev Drug Discov 2006; 5:649-59. 
1

2

3

4

Figure legend

Figure 1. Schematic representation of the complex network of survival pathways. The main pathways are shown with particular emphasis on the cross talks described in the text. 


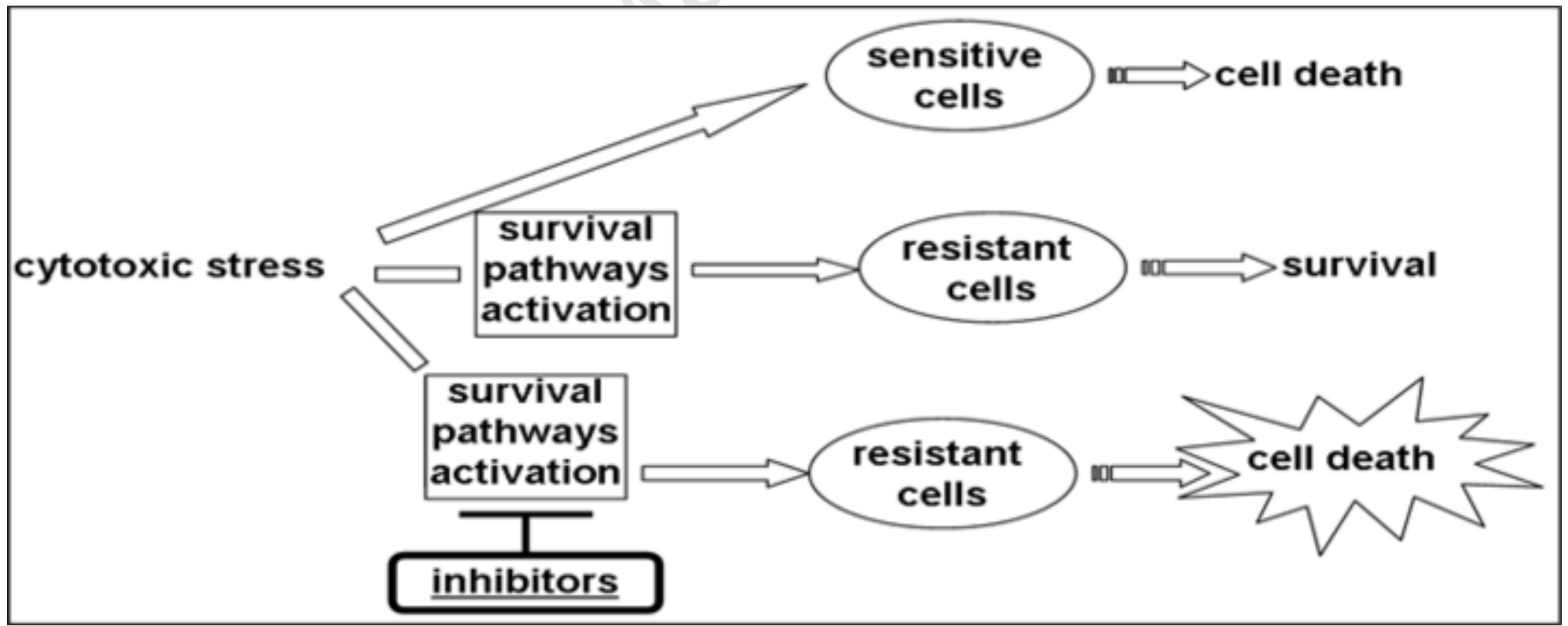




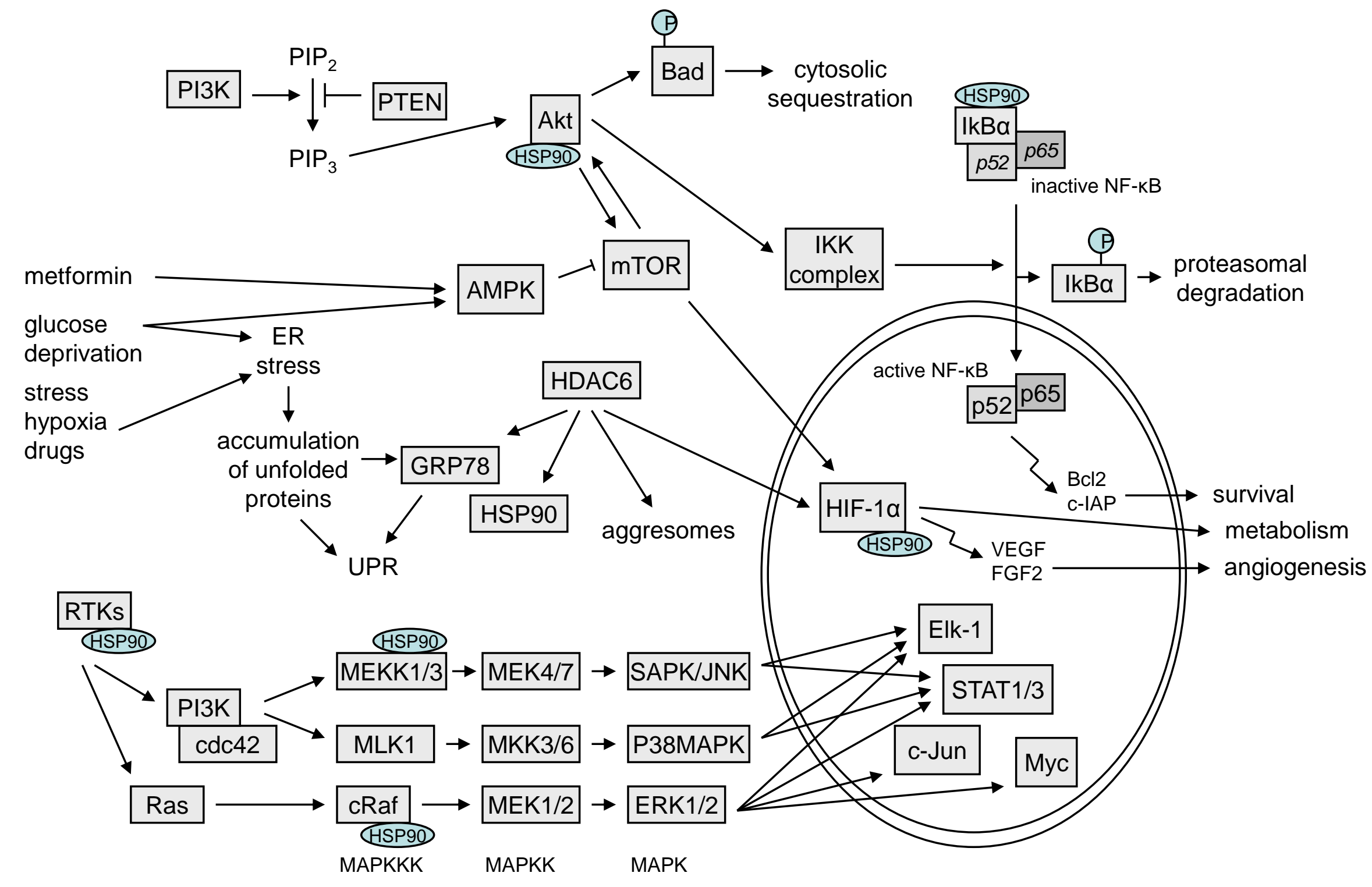

